\title{
RESPIRASI TANAH AKIBAT SISTEM OLAH TANAH DAN APLIKASI MULSA IN SITU PADA PERTANAMAN KACANG HIJAU (Vigna radiata L.) DI LABORATORIUM LAPANG TERPADU, UNIVERSITAS LAMPUNG
}

\author{
SOIL RESPIRATION DUE TO SOIL TILLAGE SYSTEM AND IN SITU MULCH \\ APPLICATION OF MUNG BEAN PLANTING (Vigna radiata L.) IN THE \\ INTEGRATED FIELD LABORATORY, UNIVERSITY OF LAMPUNG
}

\author{
Yuves Menti ${ }^{1 *}$, Sri Yusnaini ${ }^{1}$, Henrie Buchari ${ }^{2}$ dan Ainin Niswati ${ }^{2}$ \\ ${ }^{1}$ Jurusan Agroteknologi Fakultas Pertanian Universitas Lampung \\ ${ }^{2}$ Jurusan Ilmu Tanah Fakultas Pertanian Universitas Lampung \\ Jl. Prof. Soemantri Brodjonegor, No. 1, Bandar Lampung 32145 \\ *Email:yuves.menti@gmail.com
}

\begin{abstract}
Soil respiration is an indicator of the activity of microorganisms in the soil. The treatment of soil tillage system and the use of organic mulch given to the soil will affect the activity of soil microorganisms. The research aims to study the effect of soil tillage systems, application of in situ mulch, and the interaction between both in soil respiration. This research was conducted from April to July 2017 at the Integrated Field Laboratory, Faculty of Agriculture, University of Lampung, using a Randomized Block Design (RBD) factorially prepared with two treatment factors. The first factor is the soil tillage system (T), which consists of minimum tillage (T0) and conventional tillage (T1). The second factor is the treatment of mulch (M), which consists of no mulch (MO) and the application of in-situ mulch 5 t. ha-1 (M1). The data obtained were tested for various homogeneity by the Bartlett test and additivity by the Tukey test. Data were analyzed by analysis of variance and continued with LSD test at a 5\% level. The relationship between soil temperature, soil moisture content, soil organic matter, and soil $\mathrm{pH}$ with soil respiration was tested by correlation test. The results showed that the soil tillage system and application of in-situ mulch had no significant effect on soil respiration, and there was no interaction between the soil tillage system and application of in-situ mulch in soil respiration on observations before tillage, 1 day after planting (HST), 41 HST, and 88 HST. There is no correlation between soil temperature, soil moisture content, soil organic matter, and soil pH with soil respiration on pre-tillage observations, 1 HST, 41 HST, and 88 HST.
\end{abstract}

Keywords: In-situ mulch, soil respiration, soil tillage system

\begin{abstract}
ABSTRAK
Respirasi tanah merupakan indikator aktivitas mikroorganisme di dalam tanah. Perlakuan pengolahan tanah dan penggunaan mulsa organik yang diberikan ke tanah akan mempengaruhi aktivitas mikroorganisme tanah. Penelitian bertujuan untuk mempelajari pengaruh sistem olah tanah, aplikasi mulsa in situ, dan interaksi antara keduanya terhadap respirasi tanah. Penelitian ini dilaksanakan pada April sampai dengan Juli 2017 di Laboratorium Lapang Terpadu, Fakultas Pertanian, Universitas Lampung, menggunakan Rancangan Acak Kelompok (RAK) yang disusun secara faktorial dengan dua faktor perlakuan. Faktor pertama yaitu sistem olah tanah (T), yang terdiri
\end{abstract}


dari olah tanah minimum $\left(\mathrm{T}_{0}\right)$ dan olah tanah konvensional $\left(\mathrm{T}_{1}\right)$. Faktor kedua yaitu perlakuan mulsa $(\mathrm{M})$, yang terdiri dari tanpa mulsa $\left(\mathrm{M}_{0}\right)$ dan aplikasi mulsa in situ $5 \mathrm{t}$. ha ${ }^{-1}\left(\mathrm{M}_{1}\right)$. Data yang diperoleh diuji homogenitas ragamnya dengan uji Bartlett dan aditivitasnya dengan uji Tukey. Data dianalisis dengan analisis ragam dan dilanjutkan dengan uji BNT pada taraf 5\%. Hubungan antara suhu tanah, kadar air tanah, C-organik tanah, dan $\mathrm{pH}$ tanah dengan respirasi tanah diuji dengan uji korelasi. Hasil penelitian menunjukkan bahwa sistem olah tanah dan aplikasi mulsa in situ tidak berpengaruh nyata terhadap respirasi tanah, serta tidak terdapat interaksi antara sistem olah tanah dan aplikasi mulsa in situ terhadap respirasi tanah pada pengamatan sebelum olah tanah, 1 hari setelah tanamn (HST), 41 HST, dan 88 HST. Tidak terdapat korelasi antara suhu tanah, kadar air tanah, Corganik tanah, dan $\mathrm{pH}$ tanah dengan respirasi tanah pada pengamatan sebelum olah tanah, 1 HST, 41 HST, dan 88 HST.

Kata Kunci : Mulsa in situ, respirasi tanah, sistem olah tanah.

\section{PENDAHULUAN}

Tanah berfungsi sebagai media berkembangnya akar tanaman, penyedia unsur hara, dan penyimpan air bagi tanaman. Pengolahan tanah merupakan salah satu kegiatan persiapan lahan yang penting untuk menciptakan kondisi media perakaran yang mampu mendukung pertumbuhan tanaman sehingga akan diperoleh produksi tanaman yang optimal. Sistem olah tanah dalam pertanian modern dibagi menjadi dua, yaitu olah tanah konvensional dan olah tanah konservasi. Olah tanah konvensional atau dikenal juga dengan istilah olah tanah intensif(OTI) secara turun menurun masih digunakan oleh petani di Indonesia. Menurut Utomo, Buchari, dan Banuwa (2012), pada olah tanah konvensional, tanah yang telah dibersihkan dari gulma daan sisa tanaman sebelumnya diolah minimal dua kali, serta lapisan olah tanah dibuat menjadi gembur agar perakaran tanaman dapat berkembang dengan baik. Namun, olah tanah konvensional memerlukan biaya yang lebih tinggi dan akan menurunkan kualitas tanah, seperti hilangnya bahan organik tanah, meningkatkan terjadinya erosi tanah, kerusakan struktur tanah, dan memadatkan tanah sehingga dapat menurunkan produktivitas lahan.

Usaha untuk mempertahankan kualitas tanah tetap baik dapat dilakukan dengan menerapkan olah tanah konservasi. Salah satu sistem olah tanah konservasi adalah olah tanah minimum. Pada olah tanah minimum, pengolahan tanah dilakukan secara terbatas atau seperlunya di sekitar lubang tanam tanpa melakukan pengolahan tanah pada seluruh areal lahan (LIPTAN, 1994; Utomo dkk., 2012). Penggunaan mulsa organik yang berasal dari gulma dan sisa tanaman sebelumnya (mulsa in situ) juga dapat dilakukan untuk memperbaiki sifat fisik dan biologi tanah. Mulsa merupakan bahan penutup permukaan tanah yang berperan melindungi tanah dari benturan langsung butiran hujan dan aliran permukan, menekan pertumbuhan gulma, serta mampu menciptakan iklim mikro yang baik bagi tanaman dan mikroorganisme tanah.

Perlakuan pengolahan tanah dan penggunaan mulsa organik yang diberikan ke tanah akan mempengaruhi kehidupan mikroorganisme tanah. 
Tingkat aktivitas mikroorganisme di dalam tanah dapat dilihat dari laju respirasi tanah. Respirasi tanah meliputi seluruh aktivitas metabolisme di dalam tanah. Poses metabolisme tersebut menghasilkan produk sisa berupa $\mathrm{CO}_{2}$ dan $\mathrm{H}_{2} \mathrm{O}$, serta pelepasan energi. Respirasi tanah merupakan proses evolusi $\mathrm{CO}_{2}$ dari dalam tanah, terutama yang dihasilkan oleh aktivitas mikroorganisme tanah dan akar tanaman. Proses pelepasan $\mathrm{CO}_{2}$ dari dalam tanah tersebut tidak hanya dipengaruhi oleh faktor biologis (vegetasi) dan faktor lingkungan (suhu, kelembaban, $\mathrm{pH}$ ), tetapi juga faktor buatan manusia (Fang, Liu, dan Zhao, 1998) seperti sistem pengolahan tanah yang diterapkan.

Penelitian ini bertujuan untuk mempelajari pengaruh perlakuan sistem olah tanah dan aplikasi mulsa in situ, serta interaksi antara keduanya terhadap respirasi tanah pada pertanaman kacang hijau (Vigna radiata L.)

\section{BAHAN DAN METODE}

Penelitian ini dilaksanakan pada April sampai dengan Juli 2017 di Laboratorium Lapang Terpadu, Fakultas Pertanian, Universitas Lampung. Analisis respirasi tanah dan sampel tanah dilakukan di Laboratorium Ilmu Tanah, Fakultas Pertanian, Universitas Lampung.

Bahan - bahan yang digunakan dalam penelitian ini yaitu benih kacang hijau, pupuk Phonska 240 gram

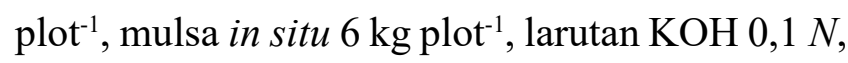
$\mathrm{HCl} 0,1 \mathrm{~N}$, indikator penolphtalein, indikator metil orange, aquades, serta bahan lain untuk analisis Corganik dan $\mathrm{pH}$ tanah. Alat - alat yang digunakan dalam penelitian ini yaitu cangkul, sabit, botol film, timbangan analitik, termometer tanah, aluminium foil, plastik, labu Erlenmeyer, gelas piala, oven, seperangkat buret, toples penyungkup, kertas label, dan alat tulis.

Penelitian ini dilakukan dengan menggunakan Rancangan Acak Kelompok (RAK) yang disusun secara faktorial dengan dua faktor perlakuan. Faktor pertama yaitu sistem olah tanah $(\mathrm{T})$, yang terdiri dari pengolahan tanah minimum $\left(\mathrm{T}_{0}\right)$ dan pengolahan tanah konvensional $\left(\mathrm{T}_{1}\right)$. Faktor kedua yaitu perlakuan mulsa (M), yang terdiri dari tanpa mulsa $\left(\mathrm{M}_{0}\right)$ dan aplikasi mulsa in situ 5 t. ha-1 $\left(\mathrm{M}_{1}\right)$. Setiap perlakuan diulang sebanyak empat kali sehingga diperoleh 16 petak satuan percobaan.

Data yang diperoleh diuji homogenitas ragamnya dengan Uji Bartlett dan aditivitas datanya dengan Uji Tukey. Apabila asumsi terpenuhi, maka dilakukan analisis ragam.

Rata-rata nilai tengah diuji dengan Uji Beda Nyata Terkecil (BNT) pada taraf 5\%. Untuk mengetahui hubungan antara suhu, kadar air, C-organik dan $\mathrm{pH}$ tanah dengan respirasi tanah maka dilakukan Uji korelasi.

Lahan yang digunakan merupakan lahan penelitian jangka panjang dari tahun 2014 dan terdiri dari 16 petak percobaan dengan ukuran tiap petaknya $3 \mathrm{~m} \times 4 \mathrm{~m}$. Pada petak olah tanah minimum, gulma dan sisa tanaman sebelumnya dikoret dan tanah diolah secara terbatas atau seperlunya yaitu hanya di sekitar lubang tanam. Pada petak olah tanah konvensional, gulma dan sisa tanaman sebelumnya dibersihkan dari lahan dan tanah diolah secara sempurna dengan dilakukan pembalikkan tanah menggunakan cangkul 
hingga tanah menjadi gembur. Aplikasi mulsa yang berasal dari gulma seperti alang - alang dan sisa tanaman musim sebelumnya yaitu tanaman jagung (mulsa in situ) dilakukan di atas permukaan tanah sebanyak 5 t. ha- ${ }^{-1}$ atau $6 \mathrm{~kg} \mathrm{plot}^{-1}$.

\section{Variabel Utama}

Respirasi Tanah. Pengukuran respirasi tanah di lapang dilakukan pada saat sebelum olah tanah, sebelum aplikasi mulsa in situ atau 1 hari setelah tanam (1 HST), fase vegetatif maksimum tanaman (41 HST), dan setelah panen (88 HST). Respirasi tanah diukur dengan metode modifikasi Verstraete (Anas, 1989) pada pagi dan sore hari. Pengukuran respirasi tanah dilakukan dengan meletakkan botol film yang berisi 10 $\mathrm{ml}$ larutan $\mathrm{KOH} 0,1 N$ di atas permukaan tanah dalam keadaan terbuka pada setiap petak percobaan. Selanjutnya ditutup dengan toples penyungkup dan toples dibenamkan ke dalam tanah sekitar $1 \mathrm{~cm}$ agar tidak ada $\mathrm{CO}_{2}$ yang keluar. Langkah yang sama dilakukan untuk kontrol, tetapi permukaan tanah terlebih dahulu ditutup dengan plastik agar $\mathrm{KOH}$ tidak dapat menangkap $\mathrm{CO}_{2}$ yang keluar dari tanah. Pengukuran ini dilakukan selama 2 jam, kemudian dianalisis di laboratorium dengan cara titrasi. Respirasi tanah dihitung dengan menggunakan rumus :

$$
\mathrm{C}-\mathrm{CO}_{2}=\frac{(\mathrm{a}-\mathrm{b}) \times \mathrm{t} \times 12}{\mathrm{~T} \times \pi \times \mathrm{r}^{2}}
$$

Keterangan :

$$
\begin{aligned}
& \mathrm{C}-\mathrm{CO}_{2}=\mathrm{mg} \mathrm{jam}^{-1} \mathrm{~m}^{-2} \\
& \mathrm{a} \stackrel{2}{=} \mathrm{ml} \mathrm{HCl} \mathrm{untuk} \mathrm{sampel} \mathrm{(setelah} \mathrm{ditambahkan} \\
& \mathrm{b}=\mathrm{ml} \mathrm{HCl} \text { untuk blanko (setelah ditambahkan } \\
& \text { metyl orange) } \\
& \mathrm{t} \quad=\operatorname{normalitas}(N) \mathrm{HCl}
\end{aligned}
$$

$$
\begin{aligned}
& T=\text { waktu }(\text { jam }) \\
& r=\text { jari-jari tabung toples }(\mathrm{m}) \\
& 12=\text { massa atom } \mathrm{C}
\end{aligned}
$$

Variabel Pendukung. Variabel pendukung yang diamati yaitu suhu tanah, kadar air tanah, Corganik tanah, dan $\mathrm{pH}$ tanah yang dilakukan bersamaan dengan pengukuran respirasi tanah yaitu pada saat sebelum olah tanah, 1 HST, 41 HST, dan 88 HST.

\section{HASIL DAN PEMBAHASAN}

\section{Respirasi Tanah pada Pertanaman Kacang Hijau (Vigna radiata $\mathbf{L}$.}

Hasil analisis ragam (Tabel 1), menunjukkan bahwa perlakuan sistem olah tanah dan aplikasi mulsa in situ 5 t. ha- ${ }^{-1}$ tidak berpengaruh nyata terhadap respirasi tanah pada pengamatan sebelum olah tanah, 1 HST, 41 HST, dan 88 HST, serta tidak terdapat interaksi antara perlakuan sistem olah tanah dan aplikasi mulsa in situ terhadap respirasi tanah pada setiap pengamatan. Belum adanya pengaruh sistem olah tanah terhadap respirasi tanah diduga akibat sistem olah tanah yang diterapkan dalam waktu singkat belum memberikan perubahan terhadap sifat-sifat tanah di lahan penelitian, sehingga belum mempengaruhi mikroorganisme yang ada di dalam tanah. Hal tersebut sesuai dengan Sucipto (2011) dan Widodo (2015) yang menyatakan bahwa penerapan perlakuan sistem olah tanah dalam kurun waktu yang singkat yaitu pada tahun pertama dan tahun ketiga di pertanaman tebu belum memperlihatkan pengaruh yang nyata terhadap kandungan bahan organik tanah. Bahan organik tanah 
Tabel 1. Ringkasan Analisis Ragam Pengaruh Sistem Olah Tanah dan Aplikasi Mulsa In Situ terhadap Respirasi Tanah pada Pengamatan Sebelum Olah Tanah, 1 HST, 41 HST, dan 88 HST pada Pertanaman Kacang Hijau (Vigna radiata L.).

\begin{tabular}{|c|c|c|c|c|}
\hline Perlakuan & Sebelum Olah Tanah & $1 \mathrm{HST}$ & $41 \mathrm{HST}$ & $88 \mathrm{HST}$ \\
\hline & \multicolumn{4}{|c|}{$\mathrm{C}-\mathrm{CO}_{2}\left(\mathrm{mg} \mathrm{jam}^{-1} \mathrm{~m}^{-2}\right)$} \\
\hline $\mathrm{T}_{0} \mathrm{M}_{0}$ & $51,99(7,05)$ & $18,62(4,22)$ & $53,28(7,20)$ & $19,90(4,39)$ \\
\hline $\mathrm{T}_{0} \mathrm{M}_{1}$ & $53,28(6,80)$ & $19,63(4,12)$ & $55,20(7,24)$ & $26,32(4,94)$ \\
\hline $\mathrm{T}_{1} \mathrm{M}_{0}$ & $36,59(5,74)$ & $28,24(5,18)$ & $59,06(7,54)$ & $25,68(5,06)$ \\
\hline $\mathrm{T}_{1} \mathrm{M}_{1}$ & $46,86(6,71)$ & $30,17(5,44)$ & $53,92(7,28)$ & $15,41(3,83)$ \\
\hline Sumber Keragaman & \multicolumn{4}{|c|}{ F hitung dan Signifikan } \\
\hline $\mathrm{T}$ & $0,34^{\text {tn }}$ & $2,54^{\operatorname{tn}}$ & $0,05^{\mathrm{tn}}$ & $0,13^{\text {tn }}$ \\
\hline $\mathrm{M}$ & $0,09^{\text {tn }}$ & $0,01^{\mathrm{tn}}$ & $0,02^{\text {tn }}$ & $0,33^{\text {tn }}$ \\
\hline $\mathrm{T} \times \mathrm{M}$ & $0,26^{\mathrm{tn}}$ & $0,06^{\mathrm{tn}}$ & $0,03^{\text {tn }}$ & $2,26^{\mathrm{tn}}$ \\
\hline
\end{tabular}

Keterangan: $\mathrm{T}_{0}=$ olah tanah minimum; $\mathrm{T}_{1}=$ olah tanah konvensional; $\mathrm{M}_{0}=$ tanpa mulsa; $\mathrm{M}_{1}=$ aplikasi mulsa in situ; $\mathrm{T}=$ sistem olah tanah; $\mathrm{M}=$ aplikasi mulsa in situ; $\mathrm{T}$ x $\mathrm{M}=$ interaksi antara sistem olah tanah dan aplikasi mulsa in situ; $\mathrm{tn}=$ tidak berpengaruh nyata pada taraf $5 \%$.

Tabel 2. Pengaruh Sistem Olah Tanah dan Aplikasi Mulsa In Situ terhadap Suhu Tanah $\left({ }^{\circ} \mathrm{C}\right)$ dan Kadar Air Tanah (\%) pada Pengamatan Sebelum Olah Tanah, 1 HST, 41 HST, dan 88 HST di Pertanaman Kacang Hijau (Vigna radiata L.).

\begin{tabular}{cccccccccc}
\hline \multirow{2}{*}{ Perlakuan } & \multicolumn{4}{c}{ Suhu Tanah $\left({ }^{\circ} \mathrm{C}\right)$} & \multicolumn{4}{c}{ Kadar Air Tanah (\%) } \\
\cline { 2 - 9 } & Sebelum Olah Tanah & 1 HST & 41 HST & 88 HST & Sebelum Olah Tanah & 1 HST & 41 HST & 88 HST \\
\hline $\mathrm{T}_{0} \mathrm{M}_{0}$ & 26,68 & 27,49 & 27,75 & 26,79 & 33,88 & 26,87 & 35,57 & 28,67 \\
$\mathrm{~T}_{0} \mathrm{M}_{1}$ & 26,05 & 27,04 & 27,06 & 26,5 & 31,08 & 26,13 & 37,08 & 26,99 \\
$\mathrm{~T}_{1} \mathrm{M}_{0}$ & 26,75 & 27,58 & 27,84 & 26,74 & 31,55 & 26,73 & 36,35 & 25,92 \\
$\mathrm{~T}_{1} \mathrm{M}_{1}$ & 26,35 & 27,84 & 27,63 & 26,65 & 30,12 & 26,57 & 36,96 & 28,33 \\
\hline
\end{tabular}

Keterangan: $\mathrm{T}_{0}=$ olah tanah minimum; $\mathrm{T}_{1}=$ olah tanah konvensional; $\mathrm{M}_{0}=$ tanpa mulsa; $\mathrm{M}_{1}=$ aplikasi mulsa in situ .

merupakan sumber energi karbon bagi mikroorganisme dalam memproduksi $\mathrm{CO}_{2}$. Dengan demikian, meningkatnya produksi $\mathrm{CO}_{2}$ akan meningkatkan respirasi tanah.

Perlakuan pemberian mulsa in situ sebanyak 5 t.ha ${ }^{-1}$ pada lahan penelitian belum memberikan pengaruh yang nyata terhadap respirasi tanah. Belum berpengaruhnya perlakuan mulsa diduga karena mulsa yang diberikan belum mampu menciptakan kondisi iklim mikro (Tabel 2 dan 3) yang sesuai untuk mikroorganisme tanah dapat aktif dan berkembang sehingga belum meningkatkan respirasi tanah. Selain itu, mulsa yang diberikan memiliki kandungan $\mathrm{C} / \mathrm{N}$ rasio yang tinggi. Kandungan $\mathrm{C} / \mathrm{N}$ rasio serasah tanaman jagung sangat tinggi yaitu 82 (Nuraida dan Muchtar, 2006) dan gulma seperti alang-alang dengan nisbah C/ N 79 (Utomo, 2012) sehingga proses dekomposisi mulsa berlangsung lambat untuk dapat menambah kandungan C-organik tanah. Hal ini sejalan dengan hasil penelitian Simamora (2015) yang menunjukkan bahwa belum adanya pengaruh dari aplikasi mulsa bagas 80 t. ha ${ }^{-1}$ terhadap respirasi tanah pada saat 
Tabel 3. Pengaruh Sistem Olah Tanah dan Aplikasi Mulsa In Situ terhadap C-organik Tanah (\%) dan pH Tanah pada Pengamatan Sebelum Olah Tanah, 1 HST, 41 HST, dan 88 HST di Pertanaman Kacang Hijau (Vigna radiata L.).

\begin{tabular}{ccccccccc}
\hline \multirow{2}{*}{ Perlakuan } & \multicolumn{4}{c}{ C-organik Tanah (\%) } & \multicolumn{5}{c}{$\mathrm{pH}$ Tanah } \\
\cline { 2 - 10 } & Sebelum Olah Tanah & 1 HST & 41 HST & 88 HST & Sebelum Olah Tanah & 1 HST & 41 HST & 88 HST \\
\hline $\mathrm{T}_{0} \mathrm{M}_{0}$ & 1,61 & 1,48 & 1,8 & 1,89 & 5,68 & 5,56 & 5,6 & 5,96 \\
$\mathrm{~T}_{0} \mathrm{M}_{1}$ & 1,56 & 1,7 & 1,88 & 1,98 & 5,63 & 5,61 & 5,71 & 6,01 \\
$\mathrm{~T}_{1} \mathrm{M}_{0}$ & 1,6 & 1,6 & 1,51 & 1,73 & 5,75 & 5,57 & 5,82 & 6,02 \\
$\mathrm{~T}_{1} \mathrm{M}_{1}$ & 1,54 & 1,75 & 1,69 & 1,94 & 5,69 & 5,61 & 5,85 & 6,08 \\
\hline
\end{tabular}

Keterangan: $\mathrm{T}_{0}=$ olah tanah minimum; $\mathrm{T}_{1}=$ olah tanah konvensional; $\mathrm{M}_{0}=$ tanpa mulsa; $\mathrm{M}_{1}=$ aplikasi mulsa in situ.

tanaman tebu berumur 7 bulan setelah ratoon kedua dan 1 bulan setelah ratoon ketiga.

Gambar 1 menunjukkan bahwa laju respirasi tanah pada saat sebelum olah tanah menunjukkan hasil yang tinggi $\left(36,59-53,28 \mathrm{mg} \mathrm{jam}^{-1} \mathrm{~m}^{-2}\right)$ dan mengalami penurunan pada saat tanaman berumur 1 HST atau 1 minggu setelah olah tanah $\left(18,62-30,17 \mathrm{mg} \mathrm{jam}^{-1} \mathrm{~m}^{-}\right.$ ${ }^{2}$ ). Tingginya laju respirasi tanah pada pengamatan sebelum olah tanah diduga karena pada lahan penelitian terdapat gulma seperti alang-alang serta sisa tanaman jagung, sehingga tingginya $\mathrm{CO}_{2}$ yang dilepaskan dari tanah berasal dari mikroorganisme tanah dan respirasi akar. Mikroorganisme dalam tanah juga biasanya terkonsentrasi pada daerah rizosfer karena akar mengeluarkan eksudat seperti asam amino, karbohidrat, vitamin, dan enzim, yang merupakan sumber energi bagi mikroorganisme tanah. Hal ini juga menyebabkan respirasi cukup aktif dilakukan oleh mikroba yang hidup di wilayah perakaran (Kelting, Burger, dan Edwards, 1998). Sedangkan pada saat tanaman berumur 1 HST, lahan baru 1 minggu diolah sehingga $\mathrm{CO}_{2}$ yang dihasilkan hanya berasal dari mikroorganisme tanah. Laju respirasi tanah pada saat tanaman kacang hijau berumur 41 HST meningkat (53,28 - 59,06 mg $\mathrm{jam}^{-1} \mathrm{~m}^{-2}$ ) dan menurun kembali pada saat tanaman berumur $88 \mathrm{HST}\left(15,41-26,32 \mathrm{mg} \mathrm{jam}^{-1} \mathrm{~m}^{-2}\right)$. Hal ini diduga karena pada pengamatan 41 HST (saat vegetatif maksimum), respirasi tanah tidak hanya dihasilkan oleh mikroorganisme tanah, tetapi juga akar tanaman kacang hijau. Hasil penelitian Crow dan Wieder (2005), menunjukkan bahwa akar tanaman menyumbang emisi $\mathrm{CO}_{2}$ sebesar $35-57 \%$. Wei, Jiang dan, Okawa (2009) menambahkan bahwa kontribusi dari respirasi akar secara rata-rata mencapai 53\% dari total emisi $\mathrm{CO}_{2}$. Namun, pada saat tanaman berumur 88 HST akar tanaman tidak lagi berkembang aktif sehingga $\mathrm{CO}_{2}$ hanya berasal dari mikroorganime tanah. Selain itu, pengukuran respirasi tanah yang dilakukan pada musim kemarau menyebabkan aktivitas mikroorganisme menurun sehingga menurunkan laju respirasi tanah. Pada kondisi lahan yang kering (Tabel 2), masalah ketersediaan air di dalam tanah berkaitan erat dengan dekomposisi bahan organik dan akitivitas mikroorganisme tanah. Dekomposisi bahan organik yang dilakukan oleh mikroorganisme tanah dapat berlangsung dengan baik bila cukup tersedia air dan 
Tabel 4. Uji korelasi antara Suhu Tanah, Kadar Air Tanah, C-organik Tanah, dan pH Tanah, dengan Respirasi Tanah.

\begin{tabular}{lcccc}
\hline \multirow{2}{*}{ Pengamatan } & \multicolumn{4}{c}{ Koefisien Korelasi (r) } \\
\cline { 2 - 5 } & \multicolumn{4}{c}{ Respirasi Tanah } \\
\cline { 2 - 5 } & Sebelum Olah Tanah & 1 HST & $41 \mathrm{HST}$ & $88 \mathrm{HST}$ \\
\hline Suhu Tanah $\left({ }^{\circ} \mathrm{C}\right)$ & $0,06^{\text {tn }}$ & $0,35^{\text {tn }}$ & $0,04^{\text {tn }}$ & $0,08^{\text {tn }}$ \\
Kadar Air Tanah (\%) & $0,29^{\text {tn }}$ & $-0,40^{\text {tn }}$ & $0,03^{\text {tn }}$ & $-0,34^{\text {tn }}$ \\
C-organik (\%) & $0,02^{\text {tn }}$ & $-0,27^{\text {tn }}$ & $-0,12^{\text {tn }}$ & $-0,10^{\text {tn }}$ \\
pH Tanah & $0,09^{\text {tn }}$ & $-0,15^{\text {tn }}$ & $0,18^{\text {tn }}$ & $0,07^{\text {tn }}$ \\
\hline
\end{tabular}

Keterangan: $\mathrm{HST}=$ hari setelah tanam; $\mathrm{tn}=$ tidak nyata.

udara di dalam tanah (Hakim dkk., 1986)

Sifat Fisik dan Kimia Tanah pada Pertanaman

\section{Kacang Hijau (Vigna radiata L.)}

Hasil pengukuran suhu tanah pada pengamatan sebelum olah tanah, 1 HST, 41 HST dan 88 HST berkisar antara $26,05{ }^{\circ} \mathrm{C}-27,84{ }^{\circ} \mathrm{C}$ (Tabel 2). Berdasarkan kisaran suhu tersebut, dapat diketahui bahwa perlakuan yang diterapkan belum mempengaruhi suhu tanah, sehingga belum berdampak pada aktivitas mikroorganisme tanah.

Hasil analisis kadar air tanah pada pengamatan sebelum olah tanah, 1 HST, 41 HST dan 88 HST berkisar antara 25,92\%-37,08\% (Tabel 2). Kadar air tanah sangat berperan bagi proses yang berlangsung di dalam tanah, khususnya yang berkaitan dengan aktivitas mikroorganisme tanah. Namun perlakuan yang diterapkan belum mempengaruhi kadar air tanah, sehingga belum berdampak pada aktivitas mikroorganisme tanah.

Hasil analisis C-organik tanah pada pengamatan sebelum olah, 1 HST, 41 HST dan 88 HST berkisar antara 1,51\% - 1,98\% (Tabel 3). Kandungan
C-organik tanah tersebut termasuk dalam kriteria Corganik yang rendah karena $<2 \%$ (Departemen Pertanian,1983 dalam Suhariyono dan Menry, 2005). Rendahnya C-organik tanah akan mempengaruhi aktivitas mikroorganisme di dalam tanah karena Corganik tanah merupakan sumber energi bagi mikrorganisme tanah dalam melakukan aktivitas hidupnya.

Hasil pengukuran $\mathrm{pH}$ tanah pada pengamatan sebelum olah tanah, 1 HST, 41 HST dan 88 HST berkisar antara 5,56-6,08 (Tabel 3). pH tanah tersebut masih dalam kriteria yang sama yaitu agak masam masam $(5,6$ - 6,5) (Departemen Pertanian,1983 dalam Suhariyono dan Menry, 2005) sehingga belum berpengaruh terhadap aktivitas mikroorganisme tanah.

Berdasarkan hasil uji korelasi pada pengamatan sebelum olah tanah, 1 HST, 41 HST, dan 88 HST menunjukkan bahwa perlakuan sistem olah tanah dan aplikasi mulsa in situ (5 t. ha-1) tidak menunjukkan korelasi yang nyata antara suhu tanah, kadar air tanah, C-organik tanah, dan $\mathrm{pH}$ tanah dengan 


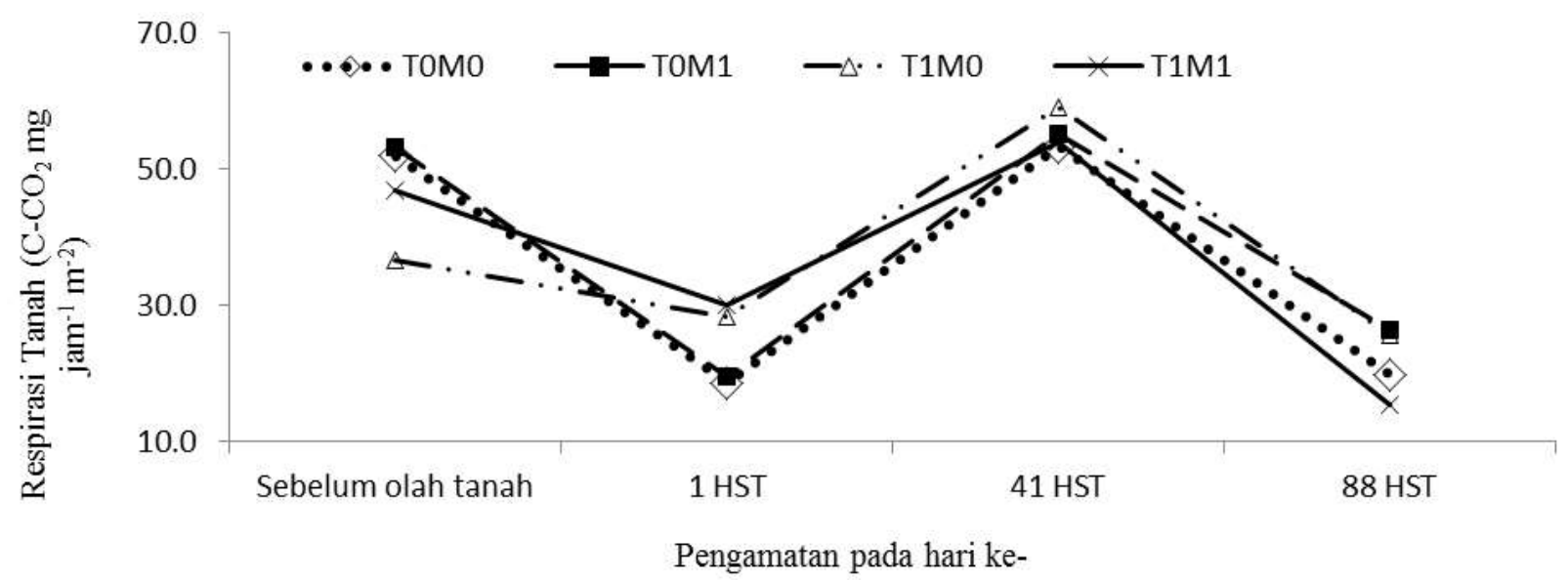

Gambar 1. Pengaruh sistem olah tanah dan aplikasi mulsa in situ terhadap respirasi tanah

respirasi tanah (Tabel 4). Artinya pada perlakuan sistem olah tanah dan aplikasi mulsa in situ $\left(5 \mathrm{t} . \mathrm{ha}^{-1}\right)$, tinggi atau rendahnya laju respirasi tanah tidak tergantung pada suhu tanah, kadar air tanah, C-organik tanah, dan $\mathrm{pH}$ tanah. Tidak adanya korelasi yang nyata antara beberapa sifat tanah dengan respirasi tanah diduga karena waktu penelitian yang singkat dan dilaksanakan pada musim tanam keenam belum menunjukkan perubahan yang signifikan terhadap beberapa sifat tanah. Selain itu, perlakuan yang diterapkan belum mempengaruhi iklim mikro tanah (Tabel 2 dan 3), sehingga belum mempengaruhi aktivitas mikroorganisme di dalam tanah. Kandungan $\mathrm{C} / \mathrm{N}$ rasio serasah jagung yang sangat tinggi yaitu 82 (Nuraida dan Muchtar, 2006) dan gulma seperti alang -alang dengan nisbah C/N 79 (Utomo, 2012) membutuhkan waktu yang lama untuk dapat terdekomposisi secara sempurna sehingga dapat menambah C-organik tanah dan unsur hara lainnya. Kandungan C-organik tanah merupakan sumber energi bagi aktivitas mikroorganisme untuk melakukan proses dekomposisi bahan organik.

\section{KESIMPULAN}

Kesimpulan dari hasil penelitian ini yaitu perlakuan sistem olah tanah tidak mempengaruhi respirasi tanah pada pengamatan sebelum olah tanah, 1 HST, 41 HST, dan 88 HST. Aplikasi mulsa in situ tidak mempengaruhi respirasi tanah pada pengamatan sebelum olah tanah, 1 HST, 41 HST, dan 88 HST. Tidak terdapat interaksi antara perlakuan sistem olah tanah dan aplikasi mulsa in situ pada pengamatan sebelum olah tanah, 1 HST, 41 HST, dan 88 HST.

\section{DAFTAR PUSTAKA}

Anas, I. 1989. Biologi Tanah dalam Praktek. Pusat antar Universitas Bioteknologi. Institut Pertanian Bogor. Bogor. $161 \mathrm{hlm}$.

Crow, S. E., dan R. K. Wieder. 2005. Sources of $\mathrm{CO}_{2}$ emissions from a northern peatland:root respiration, exudation and decomposition. Ecology, 86(7): 1825-1834. 
Fang, J., S. Liu, dan K. Zhao. 1998. Factors affecting soil respiration in reference with temperature's role in the global scale. Chinese Geographical Science, 8(3): 246-255.

Hakim, N., M.Y. Nyakpa, A. M. Lubis, S. G. Nugroho, M. R. Saul, M. A. Diha, G. B. Hong dan H. H. Bailey. 1986. Dasar - dasar ilmu tanah. Universitas Lampung. Bandar Lampung. 488 hlm.

Kelting, D. L., J. A. Burger, dan G. S. Edwards. 1998. Estimating root respiration, microbial respiration in the rhizosphere, and root-free soil respiration in forest soils. Soil Biology and Biochemistry, 30(7): 961-968.

Lembar Informasi Pertanian (LIPTAN) BIP Irian Jaya. 1994. Pengolahan Tanah Minimum (Minimum Tillage). Balai Informasi Penelitian Irian Jaya. Jayapura. $3 \mathrm{hlm}$.

Nuraida dan A. N. Mochtar. 2006. Laju dekomposisi jerami padi dan serasah jagung dengan pemberian inokulan dan pupuk hijau. Penelitian Pertanian Tanaman Pangan, 25(3): 185-189.

Simamora, D. 2015. Pengaruh Sistem Olah Tanah dan Aplikasi Mulsa Bagas terhadap Respirasi Tanah pada Lahan Pertanaman Tebu (Saccharum Officinarum L) Akhir Ratoon Kedua dan Awal Ratoon Ketiga. Skripsi. Universitas Lampung. $49 \mathrm{hlm}$.
Sucipto. 2011. Pengaruh Sistem Olah Tanah dan Aplikasi Mulsa Bagas terhadap Biomassa Karbon Mikroorganisme Tanah (C-Mik) pada Lahan Pertanaman Tebu PT Gunung Madu Plantation. Skripsi. Universitas Lampung. 58 hlm.

Suhariyono, G., dan Menry, Y. 2005. Analisis Karakteristik Unsur-unsur dalam Tanah di Berbagai Lokasi dengan Menggunakan XRF. Prosiding PPI- PDIPTN. Yogyakarta, 12 Juli 2005. Hal. 197-206.

Utomo, M. 2012. Tanpa Olah Tanah: Teknologi Pengelolaan Pertanian Lahan Kering. Lembaga Penelitian Universitas Lampung. Bandar Lampung. $110 \mathrm{hlm}$.

Utomo, M., H. Buchari, dan I. S. Banuwa. 2012. Olah Tanah Konservasi: Teknologi Mitigasi Gas Rumah Kaca Pertanian Tanaman Pangan. Lembaga Penelitian Universitas Lampung. Bandar Lampung. $94 \mathrm{hlm}$.

Wei, W., F. Jiang dan T. Okawa. 2009. Contribution of root and microbial respiration to soil $\mathrm{CO}_{2}$ efflux and their environmental controls in a humid temperate grassland of Japan. Pedosphere, 19(1): 31-39.

Widodo, E. A. 2015. Pengaruh Pengolahan Tanah dan Pemberian Mulsa Bagas terhadap Biomassa Karbon Mikroorganisme Tanah (C-Mik) pada Lahan Pertanaman Tebu PT. GMP Tahun Ketiga. Skripsi. Universitas Lampung. $39 \mathrm{hlm}$. 